\title{
Microwave absorption efficiency of poly (vinyl-butyral)/Ultra-thin nickel coated fly ash cenosphere composite
}

\author{
Angappan $\mathrm{M}^{\mathrm{a}, \mathrm{b}, 1}$, Pritom J. Bora ${ }^{\mathrm{b}, \mathrm{c}, 1}$, K.J. Vinoy $^{\mathrm{d}}$, Kishore ${ }^{\mathrm{b}}$, K. Vijayaraju ${ }^{\mathrm{e}}$, \\ Praveen C. Ramamurthy ${ }^{\mathrm{b}, \mathrm{c}, *}$ \\ ${ }^{a}$ Aeronautical Development Agency, PB No 1718, Bengaluru 560012, India \\ ${ }^{\mathrm{b}}$ Department of Materials Engineering, Indian Institute of Science, Bengaluru 560012, India \\ ${ }^{\mathrm{c}}$ Interdisciplinary Centre for Energy Research (ICER), Indian Institute of Science, Bengaluru 560012, India \\ ${ }^{\mathrm{d}}$ Department of Electrical and Communication Engineering, Indian Institute of Science, Bengaluru 560012, India \\ e Aeronautical Development Agency, PB No 1718, Bengaluru 560012, India
}

\section{A R T I C L E I N F O}

\section{Keywords:}

Fly ash cenosphere (FAC)

Ni-FAC

PVB-FAC composites

Microwave dielectrics

Microwave absorption efficiency

Reflection loss (RL)

\begin{abstract}
A B S T R A C T
The demand for light weight broadband microwave absorber is ever increasing for defence and civilian applications. A hollow microsphere filler based polymer composite system was studied in the present work owing to its attractive microwave absorbing characteristics. Poly (vinyl-butyral) (PVB) is chosen as the matrix and flyash cenosphere (FAC) is used as filler (hollow microsphere). FAC, being dielectric, is coated with Ni-P using electroless coating method to synthesize core-shell filler(magneto-dielectric). The dielectrics and microwave absorption study was carried out for the frequency range $8.2-18 \mathrm{GHz}$ (X-band and Ku-Band). The minimum reflection loss (RL) was obtained to be $-69 \mathrm{~dB}$ (thickness $1.5 \mathrm{~mm}$ ) for $\sim 665 \mathrm{~nm}$ Ni coated FAC-PVB composite. Further, this composite has excellent microwave absorption efficiency (70 dB GHz/mm). Hence, an ultra-thin Ni coated FAC loaded PVB composite is a potential candidate for broad band microwave absorption.
\end{abstract}

\section{Introduction}

There are four methods generally employed for reducing radar cross section (RCS), namely shaping, active loading, passive loading and distributed loading [1-4]. In particular, the fourth method which involves the use of microwave absorbing material (MAM) has been deployed widely along with shaping for military applications $[1,3]$. The MAM consists of dielectric/polymers such as epoxy, polyurethane, polyethylene terephthalate, rubbers, foams, polyaniline modified with conductive/magnetic fillers [1,5-9]. Their absorption performance is dependent not only on their dielectric (permittivity) and magnetic (permeability) properties but also on thickness, frequency and structure $[10,11]$. The absorbing materials need to have wide band width, light weight, lower thickness besides being cost effective. Core-shell, hollow microsphere based systems are attractive for lightweight broadband microwave absorption due to its multi phases and voids [12-15]. If MAMs are flexible, they can be possibly used as a sandwich layer in a structural member. The MAMs can be mixed with paint system and applied on external surfaces to achieve reduction in RCS. Polyvinylbutyral (PVB) is a flexible and recyclable thermo plastic which is amenable for various exciting applications starting from automobile to solar [16-19]. Due to its easy wettability and compatibility with various other polymer groups such as phenolics, epoxies, isocyanates etc., PVB is employed in many interesting functional applications such as in organic electronics. It can be also used as an adherent coating on the metal surfaces when it is mixed with suitable fillers for microwave absorbing applications $[16,17]$.

The flyash cenosphere (FAC) is an attractive filler for different applications [20-22]. FAC is a lightweight $(0.6-0.8 \mathrm{~g} / \mathrm{cc})$, hollow microsphere which was mainly made of silica and alumina [20-24]. FAC is a byproduct from thermal power plants where coal is used as fuel [20]. FACs are used in various industries due to their unique combination of spherical shape, high compression, low specific gravity, good thermal and acoustical insulation properties and inertness to acids and alkalis. These attractive properties of FAC make it an ideal candidate for making light weight and functional composites [20,25]. Literature shows that FAC containing PVB is useful for dielectrics and device encapsulation (especially organic electronics) application [26,27]. However, FAC being inert, conducting/magnetic coating is often employed to produce core-shell type composites [28-30]. Several methods such as

\footnotetext{
* Corresponding author at: Department of Materials Engineering, Indian Institute of Science, Bengaluru 560012, India.

E-mail addresses: kjvinoy@iisc.ac.in (K.J. Vinoy), balkis@iisc.ac.in (Kishore), onegroupb203@gmail.com (P.C. Ramamurthy).

${ }^{1}$ Contribution of both the authors are equal.
} 
Table 1

Details of electroless bath composition.

\begin{tabular}{lll}
\hline Sl. no. & Chemicals & Composition $(\mathrm{g} / \mathrm{l})$ \\
\hline 1 & Nickel sulfateheptahydrate $\left(\mathrm{NiSO}_{4} \cdot 7 \mathrm{H}_{2} \mathrm{O}\right)$ & $25-30$ \\
2 & Trisodium citrate & $35-40$ \\
3 & Ammonium sulfate & $10-15$ \\
4 & Sodium hypophosphite & $20-25$ \\
\hline
\end{tabular}

electroless plating, PVD, sol-gel auto-combustion method etc. are available to fabricate core-shell composites [3]. As the electroless plating process is amenable to coat both nano particles and macro structural members alike, the process can be easily adopted to industry standard [31]. Several researchers have carried out work on coated hollow microsphere. Liu et.al. [32] studied Ni coating on hollow glass microsphere for various volume fractions and coating thicknesses $(100-250 \mathrm{~nm})$ and showed a reflection loss of $35 \mathrm{~dB}$ for absorber thickness of $2 \mathrm{~mm}$ with a bandwidth of $2 \mathrm{GHz}$. Kim et al. [33] coated Ni, Co and Ni-Fe on hollow cenosphere of $50 \mu \mathrm{m}$ and shown that for the same experimental conditions, Ni-Fe coated cenosphere exhibited better impedance matching than those of $\mathrm{Co}$ and Ni coated ones where $\mathrm{Ni}$ thickness was in several microns.

The use of Ni coated FAC in PVB matrix has the potential to be a flexible light weight microwave absorber. The volume fraction of the composite was chosen so as to maintain the flexibility of the composite and filler size was chosen in alignment with the previous work [33]. The objective of this work is to optimize the electroless process parameters to coat FAC with electroless Ni-P for varying thicknesses, preparation of PVB composites and study of its microwave absorption properties.

\section{Experimental}

\subsection{Electroless preparation of Ni-FAC}

In order to functionalize the FAC, it was coated with nickel using electroless coating method. The FAC was obtained from National Thermal Power Station (NTPS), India (Raichur, Karnataka) and cleaned by the standard acid-base treatment [21]. The FAC had to be pretreated prior to electroless nickel plating. Initially, the FAC was sensitized in a solution of $18 \mathrm{~g}$ of $\mathrm{SnCl}_{2}$ and $25 \mathrm{~g}$ of $\mathrm{HCl}$ in $250 \mathrm{ml}$ of water at room temperature for $10 \mathrm{~min}$ followed by a rinsing with deionized (DI) water. This was followed by activation in the solution of $125 \mathrm{mg}$ of $\mathrm{PdCl}_{2}$ and $1.5 \mathrm{~g}$ of $\mathrm{HCl}$ in $500 \mathrm{ml}$ of water at room temperature for 10 min followed by rinsing using DI water. The pre-treated FAC was filtered and dried in oven at $100 \pm 3{ }^{\circ} \mathrm{C}$ for $30 \mathrm{~min}$. This was then transferred to electroless nickel plating bath. Electroless nickel bath composition and process parameters are given in Table 1.

\subsection{Preparation of PVB-Ni-FAC composites}

In the present study, the coating was carried out for 5, 10 and 15 min of duration. PVB-Ni-FAC composites were prepared by simple solution processing. PVB was first dissolved in ethanol and $10 \mathrm{wt} \%$ of filler (Ni-FAC) was added very slowly to PVB solution and stirred for another $30 \mathrm{~min}$. In the next step, few drops of DI water was added to the solution and poured to wave guide sample holders which were subsequently used for microwave measurement. The sample holders of size $22.68 \mathrm{~mm}$ x $10.16 \mathrm{~mm} \times 3 \mathrm{~mm}$ and $15.79 \mathrm{~mm}$ x $7.89 \mathrm{~mm} \times 3 \mathrm{~mm}$ were used for $\mathrm{X}$ and $\mathrm{Ku}$ band measurement, respectively. The casting was kept in open air drying for $48 \mathrm{~h}$. Similarly, for a comparison, PVB-FAC (uncoated) composite was also prepared and cast into sample holder. Schematic of PVB composite preparation (Fig. S1(a)), Supporting information) and the optical images of the prepared samples (Fig. S1(b) and (c)) were shown in the Supporting information. The PVB-electroless Ni coated FAC composites were respectively named as S1, S2 and S3 for 5 min Ni-FAC, 10 min Ni-FAC and 15 min-FAC. PVB-FAC composite was named as S0.

\subsection{Characterization}

The coating morphology and thickness were examined using field emission scanning electron microscopy (FESEM, Carl Zeiss). The phase composition of the coated FAC was characterized using Rigaku Smartlab X-Ray Diffractometer with Copper K $\alpha$ radiation. The coating thickness was determined by FIB cut, followed by FESEM. The complex $S$-parameters $\left(\mathrm{S}_{21}, \mathrm{~S}_{12}, \mathrm{~S}_{11}, \mathrm{~S}_{12}\right)$ were obtained from vector network analyzer (VNA, Agilent NS230A) measurements and rectangular waveguides WR-90 and WR-62 were used for the measurements in the Xband (8.2-12.4 GHz) and Ku- band (12.4-18 GHz), respectively. The complete two-port calibration of the VNA (thru-reflect-line or TRL standard) was carried out before commencing the measurements. The relative complex permittivity and complex permeability were extracted from the measured $S$-parameters using Nicholson-Ross-Weir (NRW) algorithm [34]. The experimental set-up and measurements schematic was shown in Fig. S2 (Supporting information). By using the measured values of complex permittivity and permeability, reflection loss (RL) was determined with the help of an in-house analytical procedure. The most popular and easy way to investigate the microwave absorption or EM absorption property of a material is by measuring reflection loss (RL). From application point of view, the RL of a material is important where the composite is applied as microwave absorbing layer on a
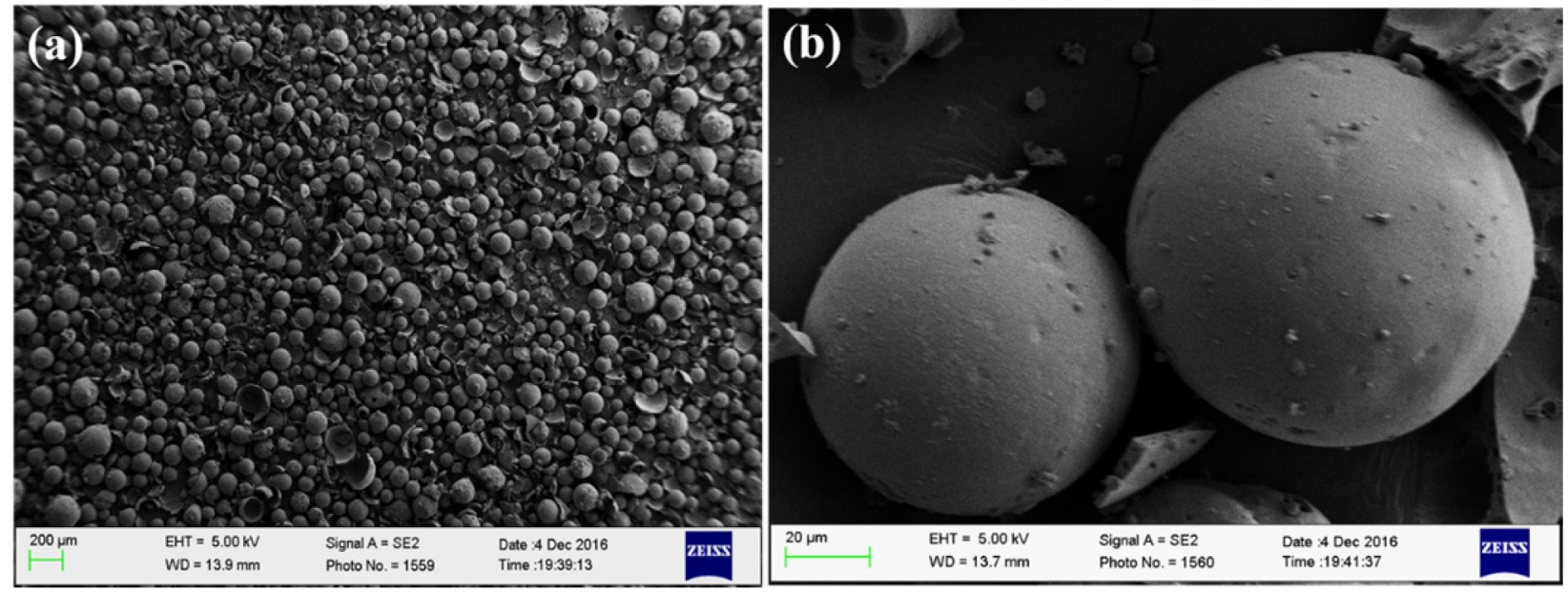

Fig. 1. Surface morphology of cleaned (a) large amount of FAC with broken FAC, (b)unbroken FAC. 


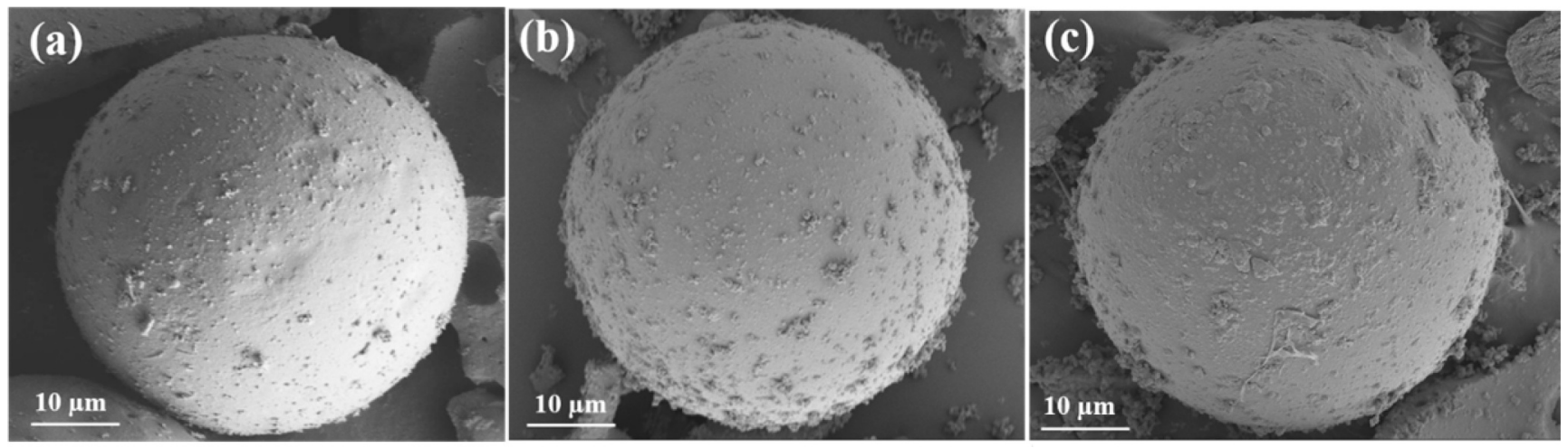

Fig. 2. FESEM images of electroless Ni-FAC for various time, viz., (a) $5 \mathrm{~min}$, (b) $10 \mathrm{~min}$ and (c) $15 \mathrm{~min}$, respectively.
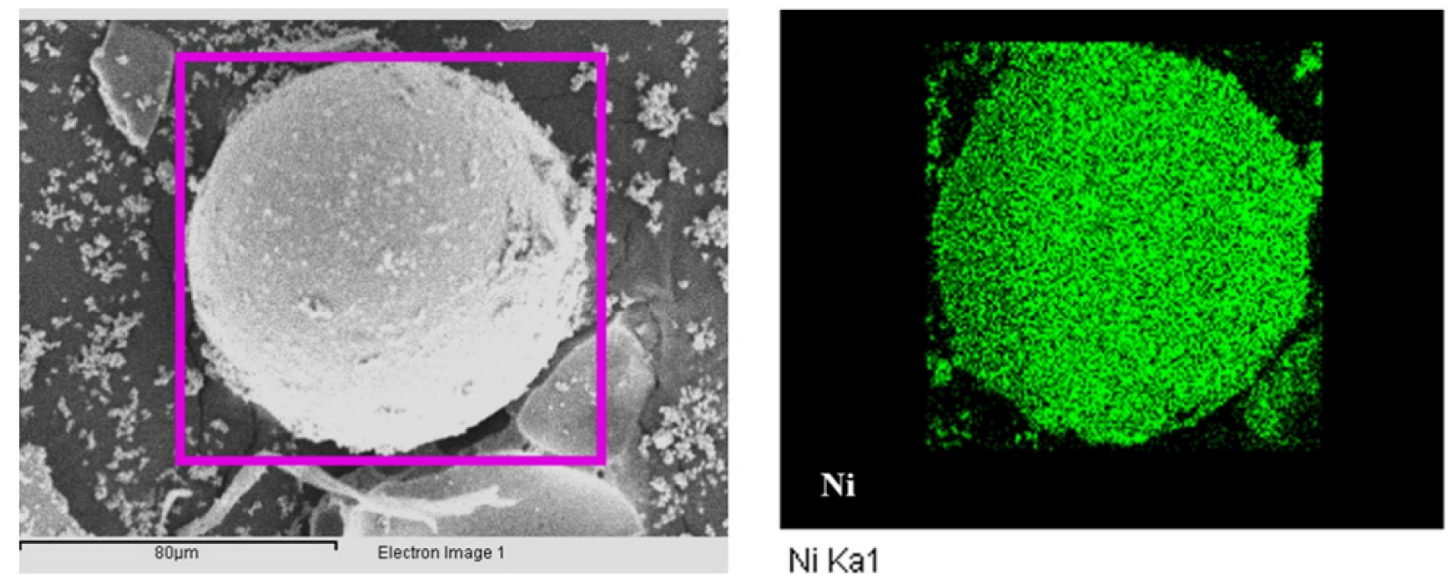

Ni Ka1

Fig. 3. FESEM image of electroless Ni coated FAC (15 min) and Ni elemental mapping.
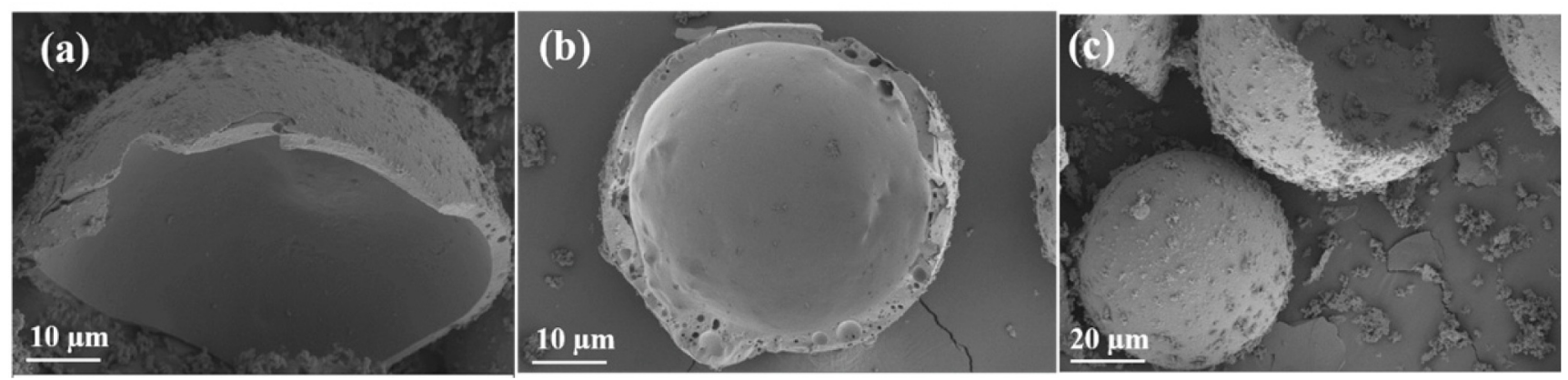

Fig. 4. The broken FESEM images of(a)5 min, (b)10 min and (c)15 min Ni-FAC, respectively.
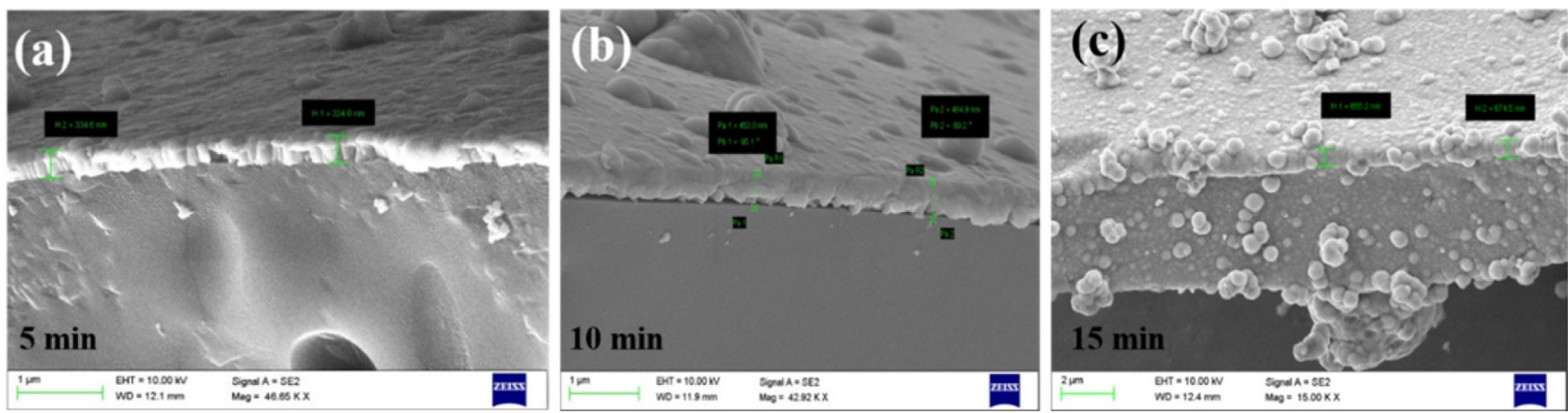

Fig. 5. The cross sectional FESEM images of (a) 5 min, (b)10 min and (c)15 min Ni-FAC respectively. 
Table 2

Obtained coating thickness of Ni over FAC for different duration during electroless method.

\begin{tabular}{lll}
\hline Serial no & Coating duration (min) & Average coating thickness (nm) \\
\hline 1 & 5 & $334 \pm 4$ \\
2 & 10 & $453 \pm 7$ \\
3 & 15 & $665 \pm 9$ \\
\hline
\end{tabular}

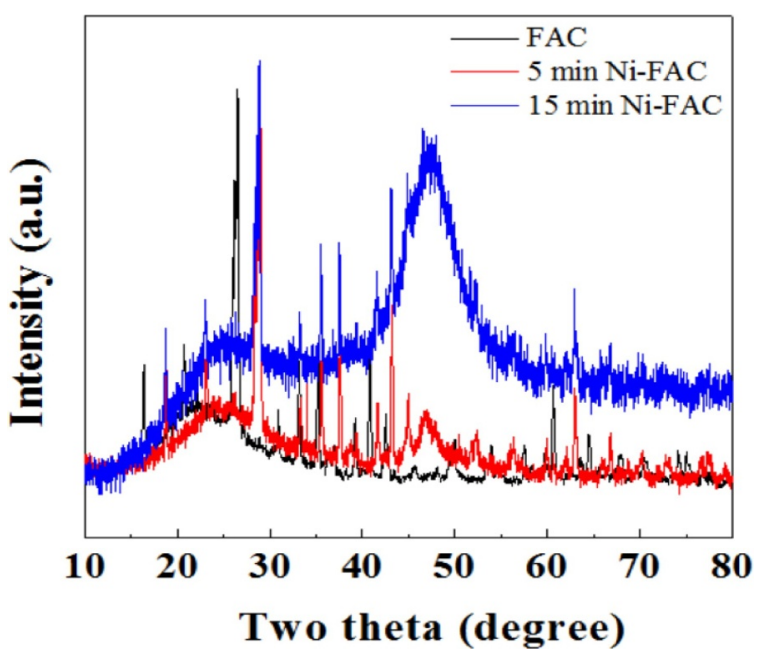

Fig. 6. Recorded XRD pattern of FAC and electroless Ni coated FAC (for different plating time).

metal substrate, a perfect electric conductor (PEC or metal) backed condition [35] such that incident microwave energy is absorbed before reaching the metal.

The RL (dB) of a material is given by following equation [35],

$R L(\mathrm{~dB})=20 \log \left|\frac{Z_{\text {in }}-Z_{0}}{Z_{\text {in }}+Z_{0}}\right|$

where, $Z_{0}(=377 \Omega)$ and $Z_{\text {in }}$ corresponds to the intrinsic impedance of free space and the composite material respectively.

The $Z_{\text {in }}$ also can be expressed as [35],

$Z_{\text {in }}=Z_{0} \sqrt{\frac{\mu_{r}}{\varepsilon_{r}}} \tanh \left(j \frac{2 \pi f t \sqrt{\mu_{r} \varepsilon_{r}}}{c}\right)$

where, $c$ is the velocity of light $\left(3 \times 10^{8} \mathrm{~ms}^{-1}\right)$ and $t$ is the thickness of the absorber. $-10 \mathrm{~dB} R \mathrm{R}$ is believed as an adequate level of absorption limit for practical applications (90\% absorption) [35-37]. In general, to investigate the microwave absorption performance of the absorbing materials, the factors should be considered are the minimal RL peak, the bandwidth ( $R L<-10 \mathrm{~dB}$ ), and the thickness of the absorber [35].

\section{Results and discussion}

The surface morphology of the cleaned FAC were shown in the Fig. 1(a) and (b), respectively. In Fig. 1(a), few broken FAC in the micrograph indicate the hollow feature of FAC. The average size of the FAC is $\sim 50 \mu \mathrm{m}$. The elemental details of the FAC were reported in our previous study [36]. The surface morphology of electroless Ni coated FAC in various time was shown in the Fig. 2(a), (b) and -(c) respectively. EDX result shows that presence of $\mathrm{Ni}$ weight $\%$ in FAC was $37 \%$, $48 \%$ and $65 \%$ for electroless time of $5 \mathrm{~min}, 10 \mathrm{~min}$ and $15 \mathrm{~min}$, respectively (Figs. S1-S3, Supporting information). Fig. 3 shows the Ni mapping over FAC coated for $15 \mathrm{~min}$. Uniform Ni coating was observed. However, few agglomerated regions were also observed. The broken NiFAC, synthesized at different conditions (different electroless time) were shown in the Fig. 4. The coating thickness was determined through FIB cut and followed by FESEM (Fig. 5).

Schematic 1.

The electroless Ni coating thickness for different times is shown in the Table 2.

To examine the phase-structure of the coated Ni-FAC, X-ray diffraction pattern was recorded and it was shown in Fig. 6. The XRD pattern of FAC is similar to the mullite [36]. In case of electroless NiFAC, the broadening of the pattern (corresponds to amorphous nature) was due to disorder of the lattice caused by phosphorous when it was accommodated by nickel [9]. A single broad peak was observed on the diffraction pattern at $45^{\circ}$ which signifies the presence of nickel at (111) plane [9]. The increased intensity of this peak with increase in coating duration indicates the enhanced nickel content in the film. The sharp peaks at $21^{\circ}, 26^{\circ}, 28^{\circ}$ and $42^{\circ}$ belongs to silica and peaks at $16^{\circ}$ and $31^{\circ}$ belongs to mullite, the major constituents of FAC [36]. The peak at $37^{\circ}$ and $71^{\circ}$ indicates the presence of magnetite and peak at $40^{\circ}$ belongs to hematite.

The cross sectional surface morphology of the as prepared S2 and S3 composite was, respectively, shown in the Fig. 7(a) and (b). Grafted PVB-Ni-FAC was observed. The cross sectional FESEM of S1 composite and corresponding elemental mapping were shown in the Fig. 8.

The microwave absorption property is strongly depending on $\varepsilon$ and $\mu$. The variation of real $\left(\varepsilon^{\prime}\right)$ and imaginary part $\left(\varepsilon^{\prime \prime}\right)$ of the complex permittivity in the frequency range $8.2-18 \mathrm{GHz}$ is shown in the Fig. 9(a) and (b), respectively. The $\varepsilon^{\prime}$ and $\varepsilon^{\prime \prime}$ were found to steadily increase with
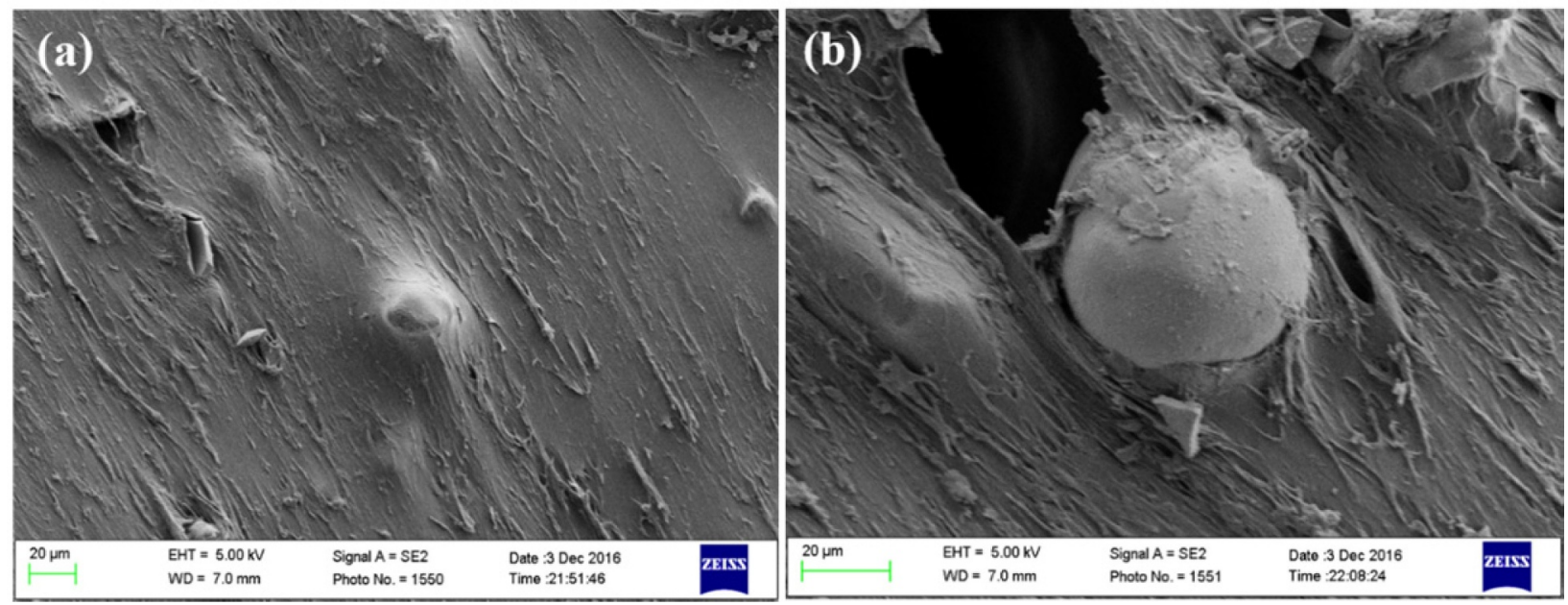

Fig. 7. Cross sectional FESEM images of (a) S2 and (b) S3 composite. 


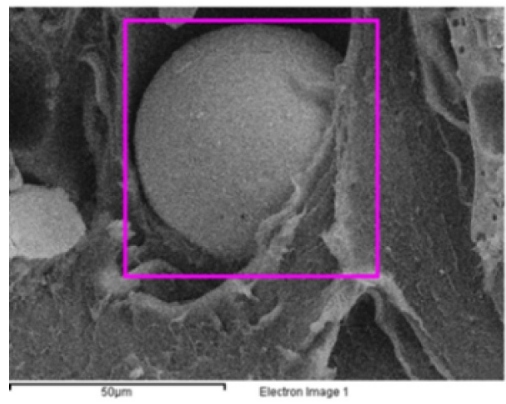

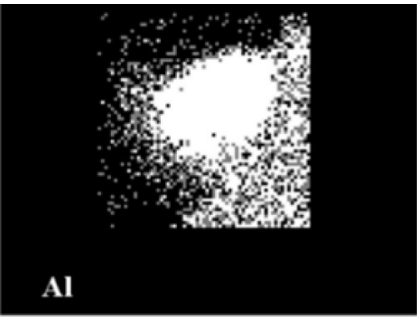

Al Ka1

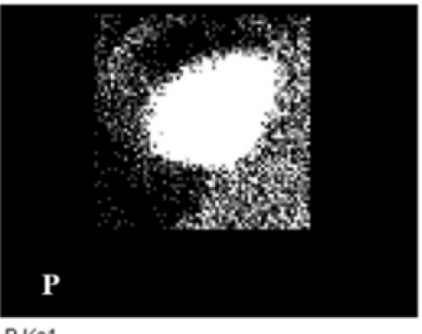

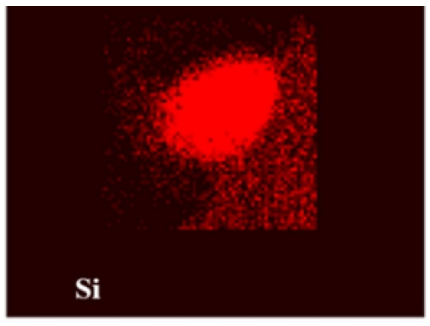

SiKa1

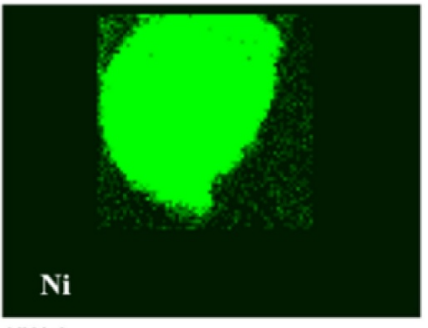

NiKa

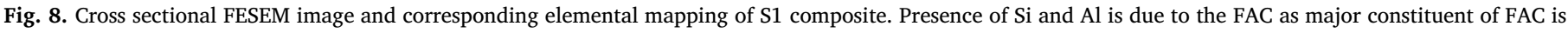
silica $\left(\mathrm{SiO}_{2}\right)$ and alumina $\left(\mathrm{Al}_{2} \mathrm{O}_{3}\right)$.
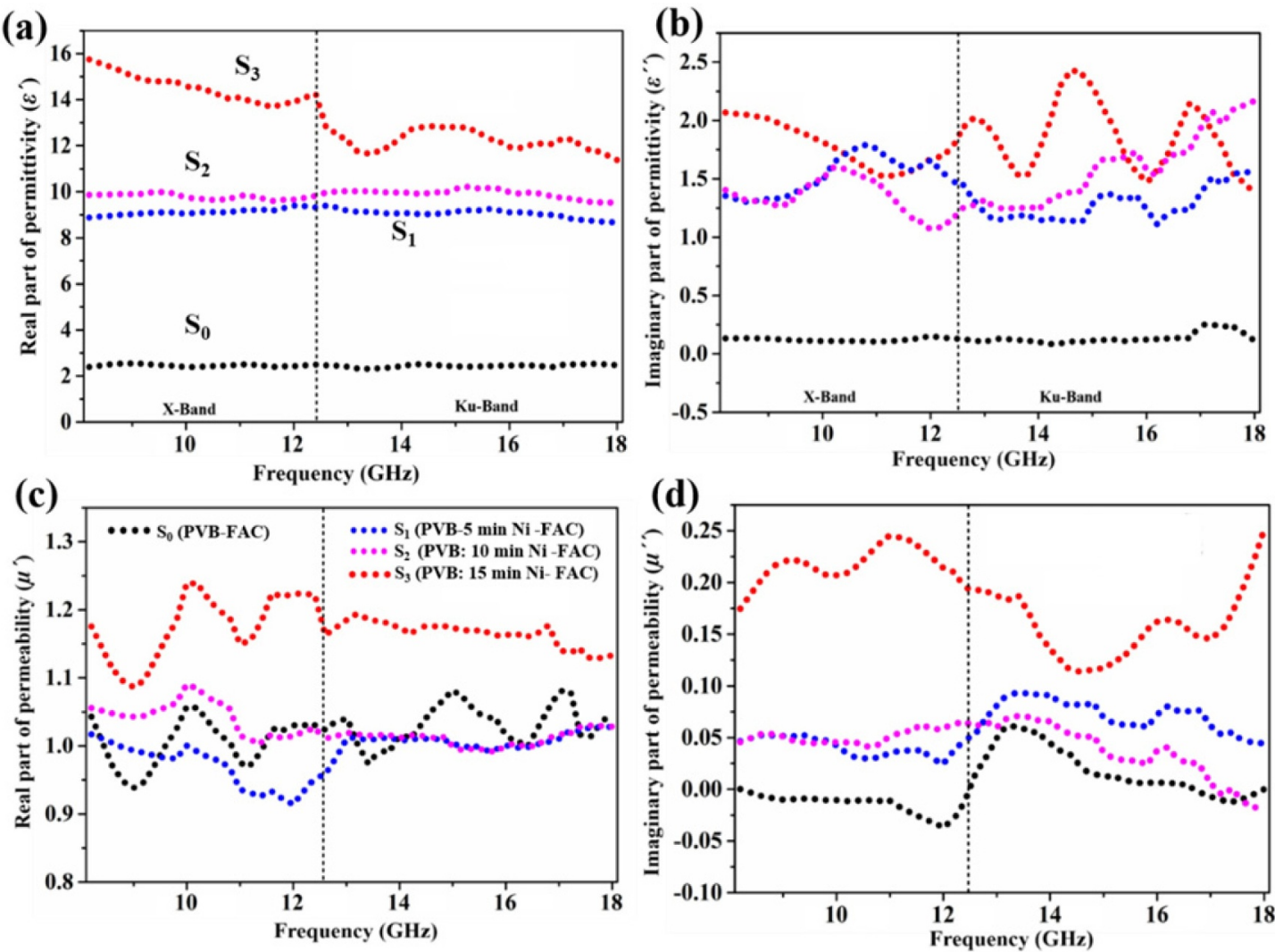

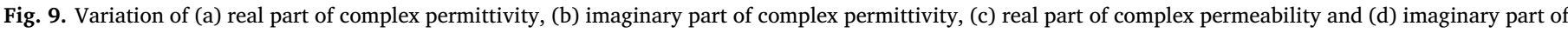
complex permeability of S0, S1, S2 and S3composites in the frequency range $(8.2-18 \mathrm{GHz})$.

increase in coating thickness. The $\varepsilon^{\prime}$ increased from $\sim 2$ of sample S0 (PVB-uncoated FAC) to 16 for sample S3 (PVB-Ni (665)-FAC) where Ni (665) refers to coating thickness of $\mathrm{Ni}$ over FAC is $\sim \mathrm{nm}$. In similar manner $\varepsilon^{\prime \prime}$ increased to $\sim 2$ for sample S3 where as it was close to zero for uncoated FAC. As $\varepsilon^{\prime}$ corresponds to storage ability of electrical energy and $\varepsilon^{\prime \prime}$ corresponds to dissipation of electric field energy of the incident wave [35], S3 composites has higher storage and dissipation capability which is aided by relatively higher coating thickness of Nickel on FAC. Slightly different trend was noticed in the case of complex permeability (Fig. 9(b) and (c)). The $\mu^{\prime}$ of coated FAC samples $\mathrm{S} 1$ and S2 did not show significant variation and remain comparable to uncoated FAC. Whereas sample S3 showed a noticeable increase. However, samples S1 and S2 showed marginal increase in imaginary permeability whereas S3 showed appreciable increase here as well.

The thickness dependency of RL (dB) value of PVB-Ni-FAC composite is highlighted in the Fig. 10. The minimum RL value of PVB-FAC was noted to be $-5.5 \mathrm{~dB}$ for the thickness $3 \mathrm{~mm}$ (thickness dependent RL of PVB-FAC was shown in Fig. S4, supporting information). As shown 

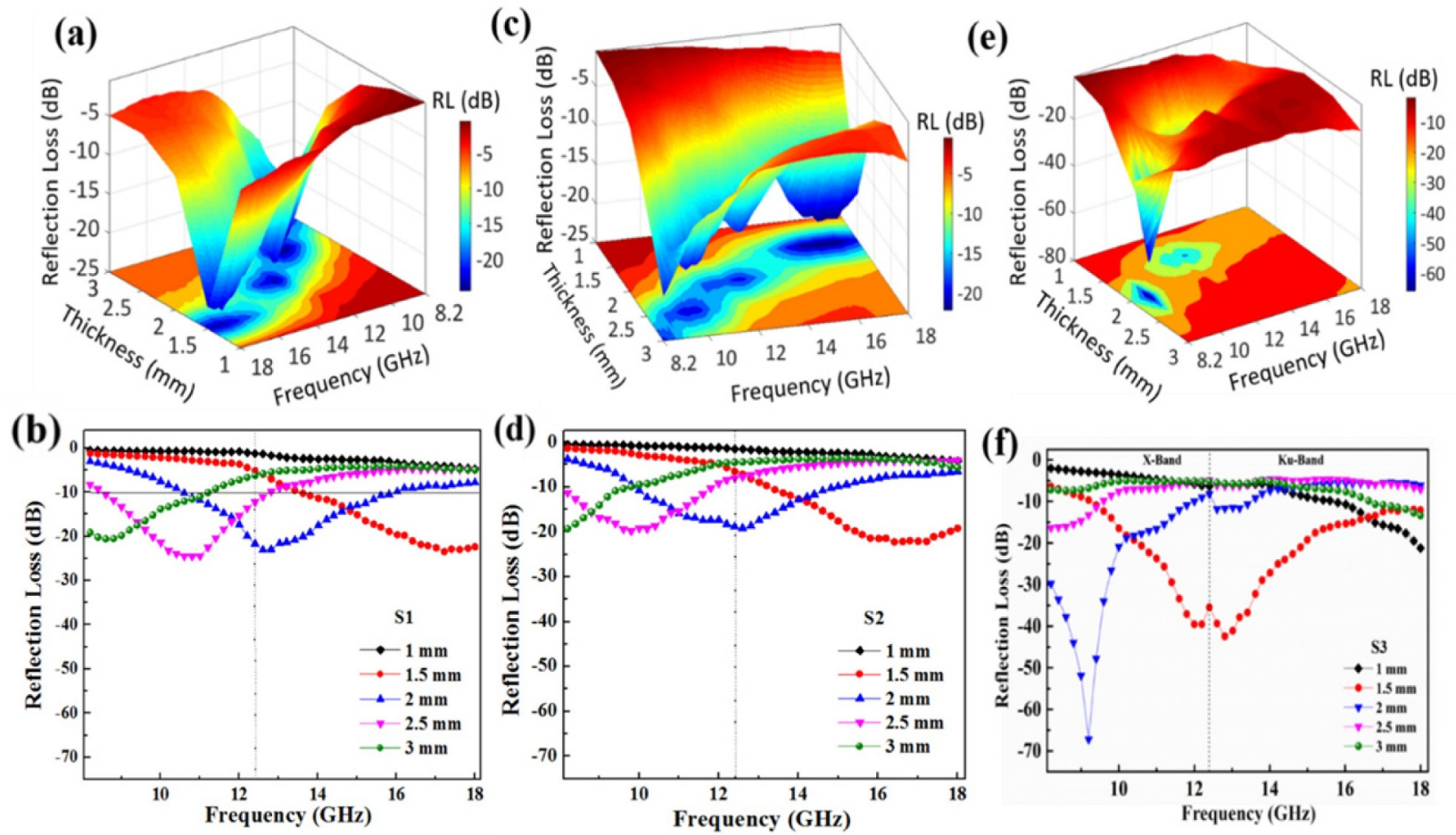

Fig. 10. Thickness dependent Reflection loss (RL in $d B$ ) of (a-b) S1, (c-d) S2 and (e-f) S3 composites in the frequency range $8.2-18$ GHz.

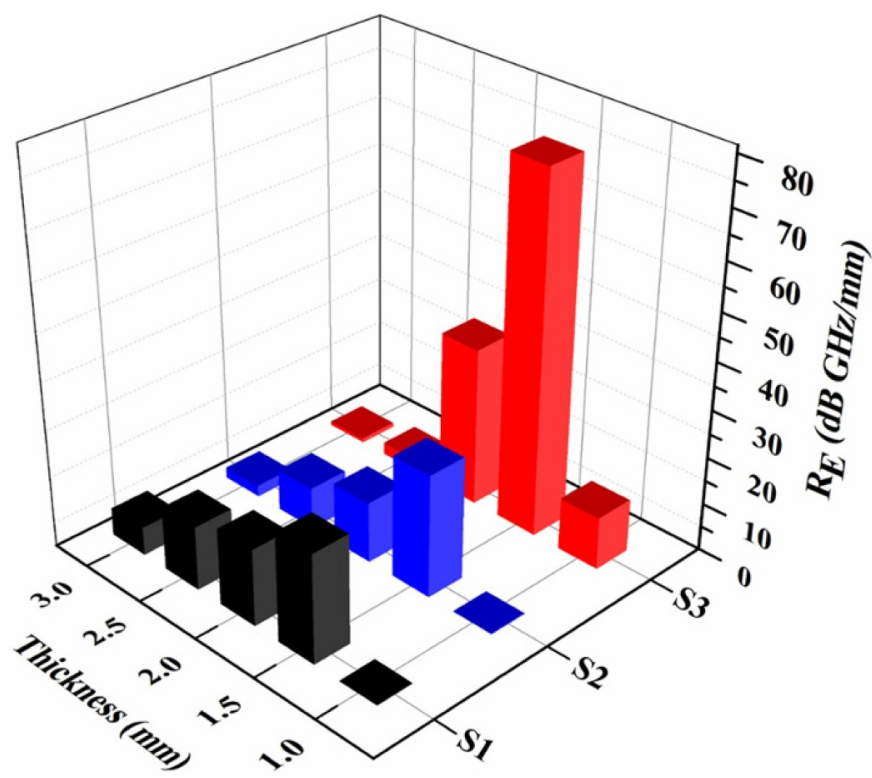

Fig. 11. The microwave absorption efficiency $\left(R_{E}\right)$ of $S 1, S 2$ and $S 3$ composites in the frequency range $8.2-18 \mathrm{GHz}$.

in the Fig. 10(a), the minimum RL value of $\mathrm{S} 1$ composite is $-25 \mathrm{~dB}$. For minimum RL of $-10 \mathrm{~dB}$, the sample with thickness $2.5 \mathrm{~mm}$ showed a bandwidth of $4 \mathrm{GHz}(8.5-12.5 \mathrm{GHz})$ while the sample with thickness of $2 \mathrm{~mm}$ showed a bandwidth of $5.5 \mathrm{GHz}(10.5-16 \mathrm{GHz})$. In both cases, the minimum RL achieved was $-25 \mathrm{~dB}$. For RL of $-10 \mathrm{~dB}$, the sample S2 with thickness of $2.5 \mathrm{~mm}$ showed bandwidth of $4 \mathrm{GHz}(8-12 \mathrm{GHz})$ and with thickness of $2 \mathrm{~mm}$ the bandwidth was $5 \mathrm{GHz}(10-15 \mathrm{GHz})$. In both the cases, the minimum RL achieved was $-20 \mathrm{~dB}$. The sample S3 with thickness of $1.5 \mathrm{~mm}$ showed bandwidth of $9 \mathrm{GHz}(9-18 \mathrm{GHz})$ with minimum RL of $-40 \mathrm{~dB}$ at $13 \mathrm{GHz}$. The sample $\mathrm{S} 3$ showed higher bandwidth with the lowest thickness among all the three samples. Moreover, the obtained minimum $\mathrm{RL}$ value was $-69 \mathrm{~dB}$ for the thickness of $2.0 \mathrm{~mm}$. The shifting of RL value towards lower frequency region with increase in absorber (composite materials S1, S2 and S3) thickness is due to the electromagnetic (EM) cancellation effect. The EM cancellation effect takes place on the surface of the absorbing composite surface if the phase difference between the incident wave and emerged wave is $180^{\circ}$ [36].

The microwave absorption efficiency $\left(\mathrm{R}_{\mathrm{E}}\right)$ is the important factor to identify the best absorbing composite which is also dependent on broad band and is expressed as, [35,36]

$\mathrm{R}_{\mathrm{E}}=\frac{\Delta S}{\mathrm{~d}}$, where, $\Delta S=\int R L d f_{R L \leq-10 d B}$

The $R_{E}$ value was calculated for S1, S2 and S3 composites to identify the best microwave absorber among these three composites in the frequency range $8.2-18 \mathrm{GHz}$ and is shown in the Fig. 11. As shown in Fig. 11 , the $R_{E}$ value is maximum for $\mathrm{S} 3$ composite $(70 \mathrm{~dB} \mathrm{GHz} / \mathrm{mm})$ with minimum thickness $(2 \mathrm{~mm})$. Thus, it indicates the excellent microwave absorption efficiency of S3 composite and most prominent for real time applications.

A comparison of hollow microsphere based systems for microwave absorption of the present work with those reported in literature is tabulated in the Table 3. It shows that, S3 composite has minimum RL value and high $R_{E}$ value as compared to previously reported composites.

The excellent microwave absorption property of the S3 composite can be understood in terms of EM power absorption and EM attenuation as well as dielectric loss tangent. The power absorbed by the S1, S2 and S3 composites were investigated by standard EM simulation (CST Microwave studio). The obtained results were shown in Fig. 12. The simulated results also indicate that the S3 composites has the highest absorption property with minimum thickness, viz.; $\sim 99 \%$ absorption can be achieved for $1.5 \mathrm{~mm}$ with a wide band width whilst S1 and S2 shows maximum absorption $\sim 90 \%$ (Fig. 12(a) and (b)).

The type of interaction Ni-FAC has with the microwave need to be examined in order to understand the possible reasons behind higher bandwidth on S3 sample. When an electromagnetic field propagates within a dielectric material, the electric field induces conduction and 
Table 3

Microwave absorption characteristics of recently reported hollow microsphere systems.

\begin{tabular}{|c|c|c|c|c|c|c|}
\hline No & Material (Hollow microsphere system) & Frequency (GHz) & Minimum RL (dB) & Thickness (mm) & $\mathrm{R}_{\mathrm{E}}(\mathrm{dB} \mathrm{GHz} / \mathrm{mm})$ & Ref \\
\hline 1 & Paraffin/ $/ \mathrm{Fe}_{2} \mathrm{O}_{3}$ - glass microsphere & $2-18$ & -20 & 2.6 & - & 13 \\
\hline 2 & Phenolic cement/ $\mathrm{CoFe}_{2} \mathrm{O}_{4}$-glass microsphere & $2-18$ & -8.3 & 1.5 & - & 12 \\
\hline 3 & Epoxy/barium ferrite coated FAC & $2-18$ & -15 & 3 & - & 15 \\
\hline 4 & Paraffin/CuS microsphere & $2-18$ & -31.5 & 1.8 & - & 37 \\
\hline 5 & Paraffin/hierarchical CuS & $2-18$ & -17.5 & 1.3 & 11.39 & 38 \\
\hline 6 & Paraffin/Ni@void@SnO 2 & $2-18$ & -35.5 & 1.9 & 34.18 & 35 \\
\hline 7 & $\mathrm{PVB} / \mathrm{CoOx}-\mathrm{FAC}$ & $12-18$ & -27 & 2.5 & 25.35 & 36 \\
\hline 8 & PVB/NiO-FAC & $12-18$ & -47.5 & 2.5 & 53.7 & 36 \\
\hline \multirow[t]{2}{*}{9} & PVB/Ni-FAC & $8.2-18$ & -45.5 & 1.5 & 70 & This work \\
\hline & & $8.2-18$ & -69 & 2 & 35.5 & \\
\hline
\end{tabular}
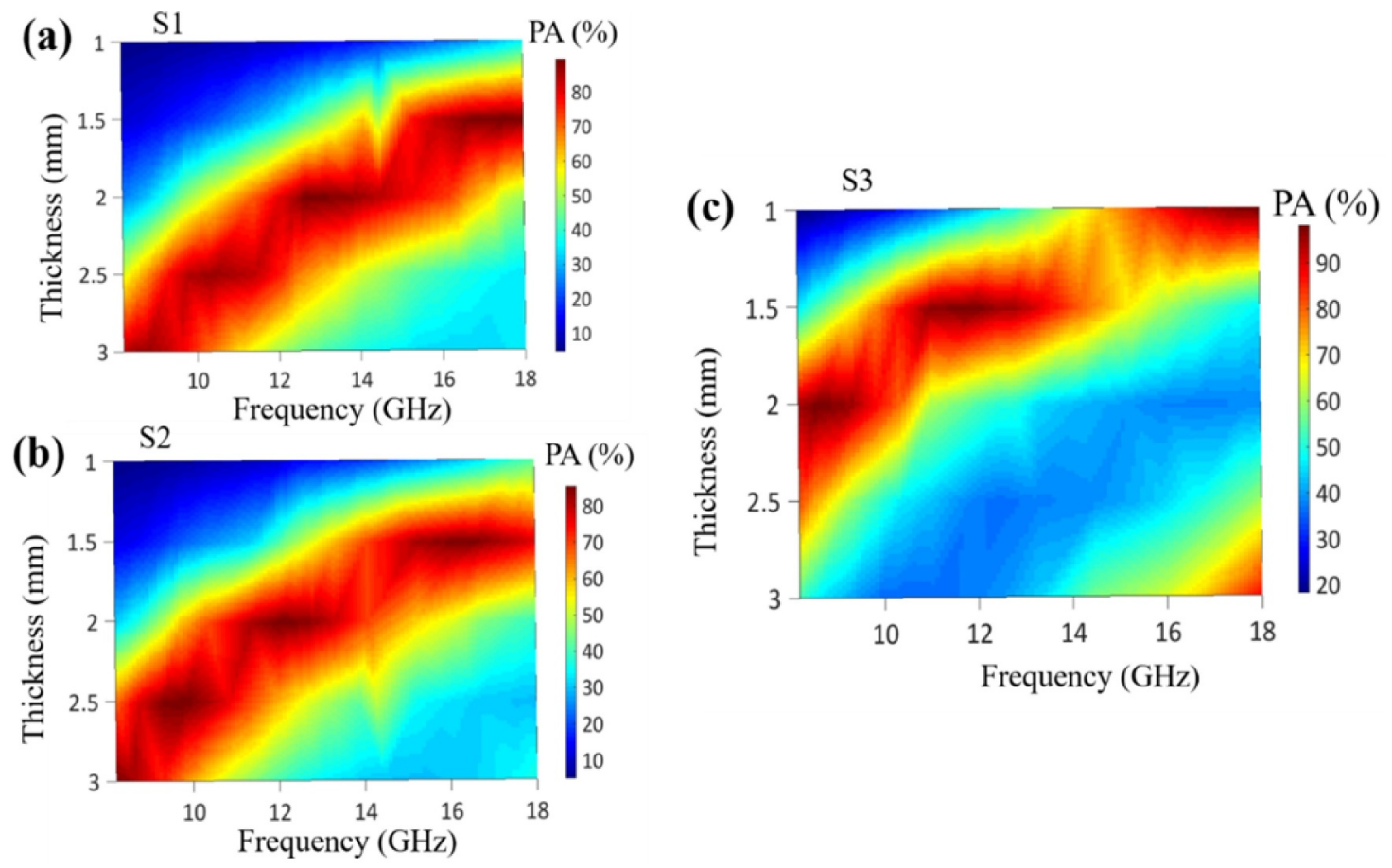

Fig. 12. Power absorbed (PA\%) by (a) S1, (b) S2 and (c) S3 composites in the 8.2-18 GHz.

displacement currents. The conduction due to free electrons results in $I^{2} R$ loss and any increased conductivity would result in significant in $I^{2} R$ loss. Interaction of bound charges with EM waves results in displacement current. This interaction can be attributed to various polarization effects such as electronic polarization, atomic polarization, relaxation polarization, orientation polarization and space charge polarization. However, it is possible that all these types of polarization need not be active in the entire electromagnetic spectrum under study. This means that in different bandwidths, combination of all or a few of the above polarization effects could be active. This is expected due to increased phase lag between the oscillating electric field and reorientation of the polarization to the initial state. Due to the increased phase lag, electronic polarization and atomic polarization may not be exhibited by dielectric materials in the microwave frequency range. Further, as there are no polar molecules present in the PVB-FAC system, orientation polarization is also not feasible. It is reported that the dielectric loss tangent due to space charge polarization/interfacial polarization varies significantly as a function of the conductivity and dielectric properties of the material in microwave frequency range [38-43]. The charge accumulation in Ni film separated by insulating PVB matrix is proportional to the film thickness. Higher permittivity of S3 would increase the capacitance of the composite and result in increase of space charge polarization. Therefore, it appears that the space charge polarization/interfacial polarization is the main dielectric loss mechanism contributing to the significant microwave absorption observed in S3 sample.

Improvement in dielectric loss compared to pristine composites observed in all the three functionalized specimens were similar as seen in Fig. 13(a) whereas magnetic loss tangent of sample S3 was noticeably higher than other samples (Fig. 13(b)). Hence, there is a need to consider other loss mechanisms which are relevant to the present study so as to ascertain the reasons behind higher loss in sample S3. When the oscillating microwave is incident on the Ni-FAC filled polymer composite, the charges would get accumulated in the interface of polymernickel coated layer. Due to higher operating frequency, the inadequate relaxation time or phase lag would result in dielectric loss. In addition, the presence of free charge carriers in nickel coating would also lead to conduction loss. The increased coating thickness would increase the interfacial area besides yielding more free electrons which was schematically depicted in Fig. 14. Both the factors will contribute to the increase of conduction and dielectric losses. These losses lead to higher electromagnetic (EM) attenuation. According to the transmission line theory, 

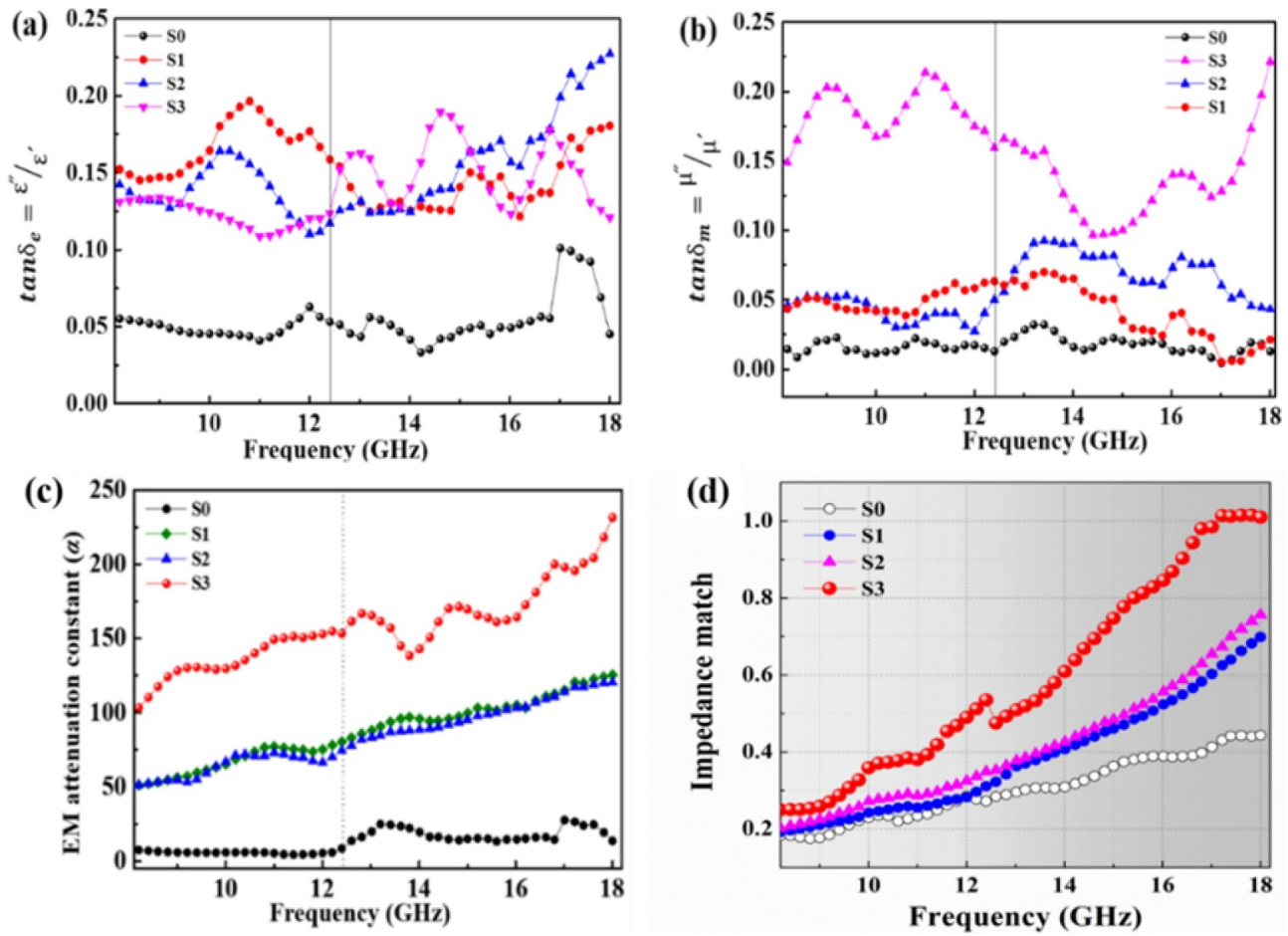

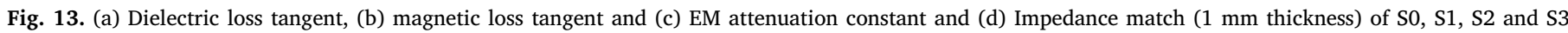
composites in the frequency range $8.2-18 \mathrm{GHz}$.

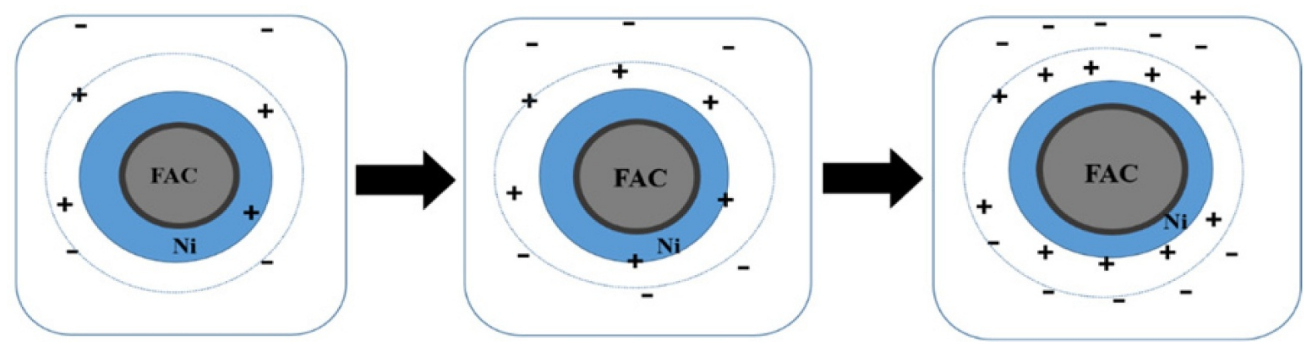

Fig. 14. Schematic showing the effect of space charge (interface) polarization with increase in coating thickness.
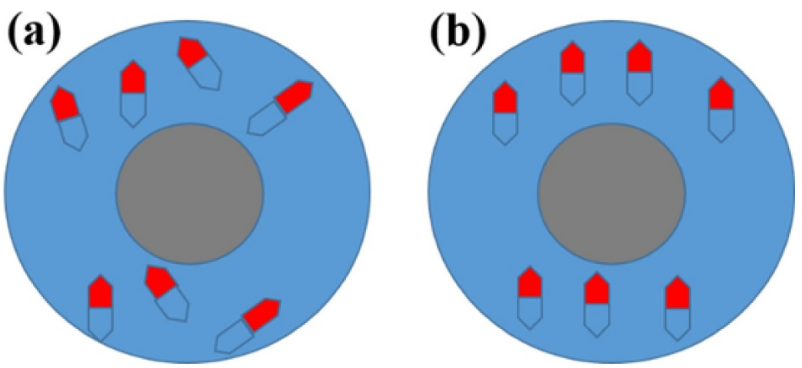

Fig. 15. Schematic showing the effect of magnetic loss to (a) without application of field(b) with application of field.

EM attenuation constnt $(\alpha)=\frac{2 \pi f}{\sqrt{2} c}$

$$
\times\left[\left(\mu^{\prime \prime} \varepsilon^{\prime \prime}-\mu^{\prime} \varepsilon^{\prime}\right)+\left\{\left(\mu^{\prime \prime} \varepsilon^{\prime \prime}-\mu^{\prime} \varepsilon^{\prime}\right)^{2}+\left(\mu^{\prime} \varepsilon^{\prime \prime}+\mu^{\prime \prime} \varepsilon^{\prime}\right)^{2}\right\}^{\frac{1}{2}}\right]^{\frac{1}{2}}
$$

The calculated EM attenuation constant $(\alpha)$ values were shown in the Fig. 13(c). As observed in Fig. 13(c), for S3 composites $\alpha$ value was predominant (100-227) and resulted in high EM attenuation than others. To better understand the microwave absorption property of the Ni-FAC composites, the impedance match, $Z_{i m} / Z_{0}$, of the S0, S1, S2 and

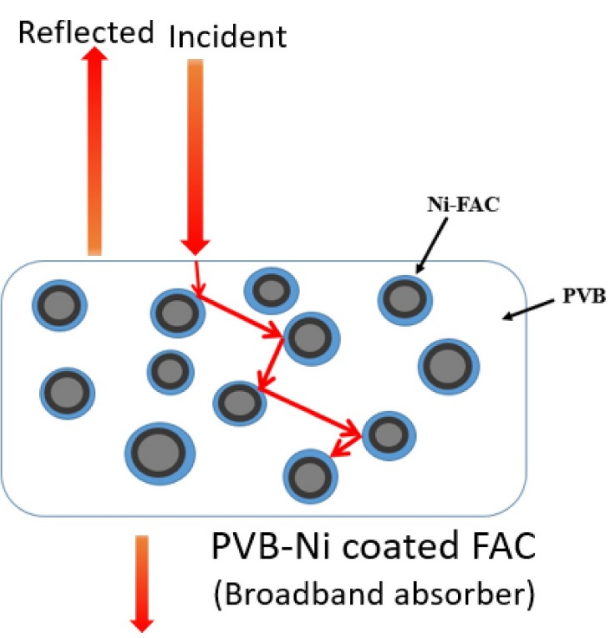

Transmitted

Fig. 16. Schematic of loss mechanism due to multiple reflection.

S3 composites $(1 \mathrm{~mm})$ were calculated. As shown in the Fig. 13(d), the impedance match value was remarkably better for S3 composite (impedance matching band closes to 1 ) as compared to the others. Thus, it 


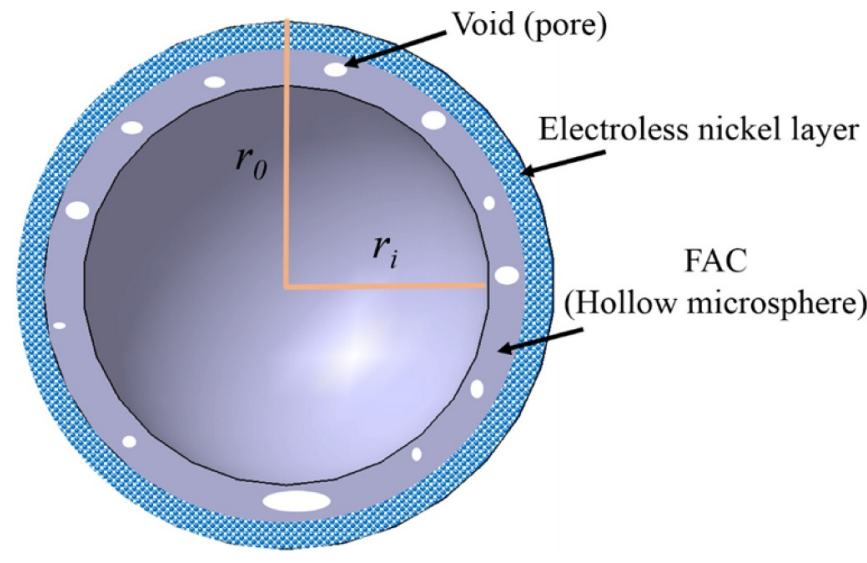

Fig. 17. Cross-sectional schematic of electroless nickel coated FAC structure.

would aid the incident electromagnetic wave to propagate into the S3 composite (absorption structure) with less reflections as compared to the S0, S1 and S2 composites.

Apart from the above discussion, increase in magnectic loss tangent for sample S3 as seen in Fig. 13(b) suggests that higher coating thicknesses lead to higher magnetic losses. It is known that the magnetic domain aligment in the presence of EM field asschematically shown in Fig. 15 and consequent hysteresis that developes during realignment would result in loss $[44,45]$. Also, peaks can be seen in Fig. 13(b) at frequency 9, 11 and $17 \mathrm{GHz}$. These resonance peaks appearing at high frequencies may be due to natural resonance and would further enhance the magnetic loss. The contribution due to significant losses accumulated due to dielectric loss, conduction loss and magnetic loss have led to increased total loss for sample S3. Apart from this, another possible contribution from propogation losses as a resultof multiple reflections encountered by microwave is schematically shown in Fig. 16. The loss arising from these sources along with magnetic loss as explained above may be the reason for higher RL and larger bandwidth with lower thickness exhibited in the case of sample S3. Finally, the hollow regions also helping to trap the incident electromagnetic wave.

The radius of the hollow microsphere also affects the microwave absorption property, and hence FAC size (radius) is also an important factor here [46]. In case of electroless $\mathrm{Ni}$ coated FAC, FAC radius $(\sim$ $25 \mu \mathrm{m})$ was much higher than the FAC shell thickness $(\sim 2 \mu \mathrm{m})$, and over there nickel was coated $(\sim 665 \mathrm{~nm})$. The cross-sectional schematic of the core-shell Ni-FAC structure was shown in Fig. 17.

According to the effective medium theory, in the case of a core-shell structure, the effective permittivity intrinsically depends on the factor, $r_{0}-r_{i} / r_{i}$ (Fig. 17) [46]. It should be noted that, in this case, in the region $r_{0}-r_{i}$, the effective medium consists of FAC shell and electroless nickel. In addition, some voids might present at the FAC shell. Thus, NiFAC structure is not a conventional micro-nano based core-shell structure, where size (radius) of FAC is also contributing for better microwave absorption through effective permittivity.

The effect of nickel coating thickness on FAC, for microwave absorption performances also can be described based on the model proposed by Bychanok et al. [14]. According to that, better microwave absorption performance of hollow microspheres is also due to the central region (void) as it possesses a constant refractive index (RI) and because of this spatial dispersion is predominant [14]. In this case, the expected maximum RI $\left(n_{h}\right)$ value of Ni-FAC hollow microsphere is [14],

$n_{h}(f)=\left[n_{s}(f) \pi\left(r_{0}^{2}-r_{i}^{2}\right)+n_{o}\left(4 r_{0}^{2}-\pi\left(r_{0}^{2}-r_{i}^{2}\right)\right] / 4 r_{0}^{2}\right.$

where, $n_{s}(f)$ is the RI of the coated region and $n_{o}$ is RI of air $(=1) . r_{i}$ and $r_{o}$ corresponds to inner and outer radii respectively. Based on this, optimal nickel coating over FAC for better microwave absorption can be approximated. Theoretically, $500-700 \mathrm{~nm}$ nickel coating over FAC is advantageous for better microwave absorption and $\sim 650 \mathrm{~nm}$ coating exhibits better absorption bandwidth at minimum thickness. It was observed that, while thickness was increased, the RL value was not decreased significantly. As a case study, for 20 min electroless Ni coating ( $\mathrm{Ni}$ coating thickness $\sim 900 \mathrm{~nm}$ ), the RL value was obtained to be $-18 \mathrm{~dB}$ (for $2 \mathrm{~mm}$ ) and bandwidth is very narrow (Fig. S7, Supporting information). While Ni coating thickness as increased over FAC (above optimal coating thickness), the reflection and scattering of incident microwaves were more predominant and due to that lesser energy entered into the composite hollow structure (Ni-FAC) resulting in lesser absorption [36].

\section{Conclusions}

The Ni coating over FAC by electroless method and PVB-Ni-FAC composite was preapared by simple solution processing. It has been demonstrated in the present study that it is possible to realise polymer based composite materials for wide bandwidth microwave absorbtion by varying the coating thickness of Ni layer on FAC. The possible mechanisms which are likely to be presentin Ni-FAC filled polymer composites have been discussed in detail. Amongst the combination of composite thicknesses and coating thicknesses, the S3 configuration with $665 \mathrm{~nm}$ Ni coated FAC loaded PVB composite in general results in higher microwave absorption. In particular, composite thickness in the range of $1.5-2.0 \mathrm{~mm}$ results in $\mathrm{RL}$ of $-40 \mathrm{~dB}$ and $-69 \mathrm{~dB}$, respectively. In view of excellent $R L$ and $R_{E}$ values exhibited in these composites with wider bandwidth microwave absorbtion, it is suggested that this class of Ni-FAC filled polymer composites can be a potential material system for microwave absorbtion applications.

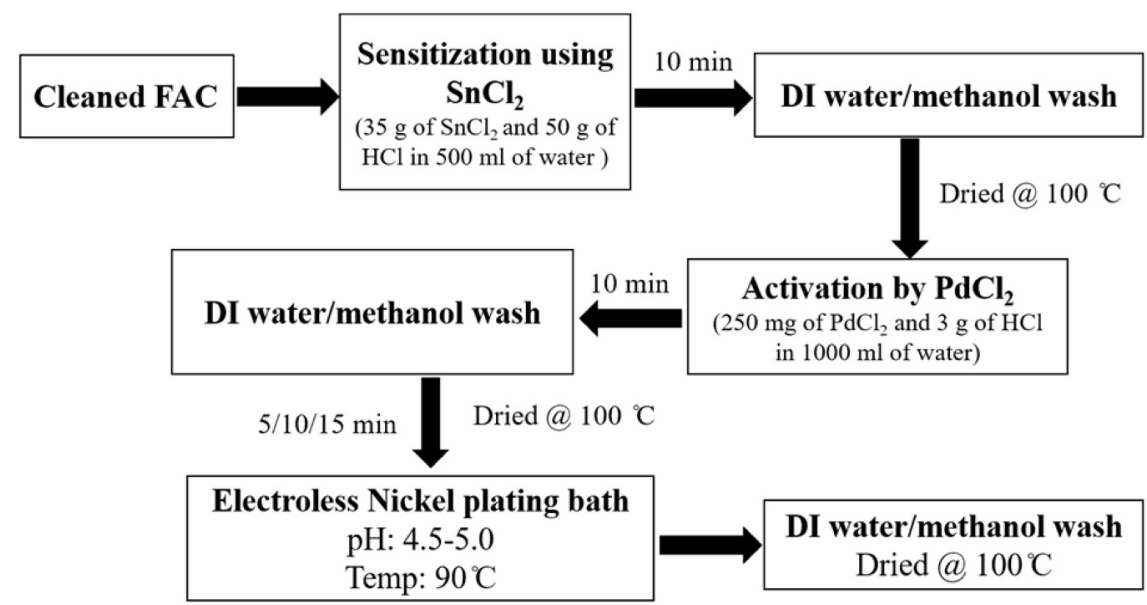

Schematic 1. Flow-chart and Schematic of Ni coating on FAC through electroless method. 


\section{Supporting information}

Schematic and digital photo of composites and measurements setup. EDX results of various Ni coated FAC. Thickness dependent reflection loss (RL) of PVB-FAC composite.

\section{Declaration of Competing Interest}

None.

\section{Acknowledgements}

Authors gratefully acknowledge the technical support from MNCF (CeNSE) for this work. Kishore would like to place on record the AICTE for offering Emeritus position. authors would like to acknowledge Government of India, Ministry of defence Aeronautics Research \& Development Board (ARDB/01/2031900/M/I) for financial support of this work.

\section{Supplementary materials}

Supplementary material associated with this article can be found, in the online version, at doi:10.1016/j.surfin.2020.100430.

\section{References}

[1] K.J. Vinoy, R.M. Jha, Radar Absorbing Materials: From Theory to Design and Characterization, Springer, US, 2011.

[2] H. Xu, X. Yin, M. Zhu, M. Han, Z. Hou, X. Li, L. Zhang, L. Cheng, ACS Appl. Mater. Interfaces 9 (2017) 6332-6341.

[3] Y. Wang, T. Li, L. Zhao, Z. Hu, Y. Gu, Energy Power Eng 3 (2011) 580-584.

[4] L.S. Rashid, A.K. Brown, 8th Eur. Radar Conf. 2011 2011, pp. 97-100.

[5] Z. Wang, G. Zhao, Open J. Compos. Mater. 3 (2013) 17-23.

[6] F. Qin, C. Brosseau, J. Appl. Phys. (2012) 111.

[7] K. Lakshmi, H. John, K.T. Mathew, R. Joseph, K.E. George, Acta Mater. 57 (2009) 371-375.

[8] S.S. Kim, S.B. Jo, K.I. Gueon, K.K. Choi, J.M. Kim, K.S. Churn, IEEE Trans. Magn. 27 (1991) 5462-5464.

[9] M. Angappan, P.J. Bora, K.J. Vinoy, K. Vijay Raju, Praveen C Ramamurthy, Compos. Commun. 10 (2018) 110-115.

[10] L. Huang, Y. Duan, X. Dai, Y. Zeng, G. Ma, Y. Liu, S. Gao, W. Zhang, Small 15 (2019) 1902730 .

[11] B. Zhao, B. Fan, Y. Xu, G. Shao, X. Wang, W. Zhao, R. Zhang, ACS Appl. Mater. Interfaces 7 (2015) 26217-26225.

[12] W. Fu, S. Liu, W. Fan, H. Yang, X. Pang, J. Xu, G. Zou, J. Magn. Magn. Mater. 316 (2007) 54-58.

[13] J. Wei, J. Liu, S. Li, J. Magn. Magn. Mater. 312 (2007) 414-417.

[14] D. Bychanok, S. Li, A. Sanchez-Sanchez, G. Gorokhov, P. Kuzhir, F.Y. Ogrin, A. Pasc, T. Ballweg, K. Mandel, A. Szczurek, V. Fierro and A. Celzard, Appl. Phys. Lett., DOI:10.1063/1.4938537.
[15] Q. Li, J. Pang, B. Wang, D. Tao, X. Xu, L. Sun, J. Zhai, Adv. Powder Technol. 24 (2013) 288-294.

[16] P.J. Bora, I. Azeem, K.J. Vinoy, P.C. Ramamurthy, G. Madras, Compos. Part B Eng. 132 (2018) 188-196.

[17] P.J. Bora, M. Porwal, K.J. Vinoy, P.C. Ramamurthy, G. Madras, Mater. Res. Express 3 (2016) 095003.

[18] P.J. Bora, G. Lakhani, P.C. Ramamurthy, G. Madras, RSC Adv. 6 (2016) 79058-79065.

[19] K. Nakane, T. Kurita, T. Ogihara, N. Ogata, Compos. Part B Eng. 35 (2004) 219-222.

[20] N. Ranjbar, C. Kuenzel, Fuel 207 (2017) 1-12.

[21] P.J. Bora, K.J. Vinoy, P.C. Ramamurthy, Kishore, G. Madras, Compos. Commun. 4 (2017) 37-42.

[22] M. Kulkarni, Kishore, J. Appl. Polym. Sci. 84 (2002) 2404-2410.

[23] A. Kumar, Industrial Pollution: Problems and Solutions, Daya Publishing House, 2006.

[24] Z.T. Yao, X.S. Ji, P.K. Sarker, J.H. Tang, L.Q. Ge, M.S. Xia, Y.Q. Xi, Earth-Sci. Rev. 141 (2015) 105-121.

[25] R.N. Lieberman, Y. Anker, O. Font, X. Querol, Y. Mastai, Y. Knop, H. Cohen, Environ. Sci. Technol. 49 (2015) 14146-14155.

[26] A.S. Roy, S. Saravanan, Kishore, P.C. Ramamurthy, G. Madras, Polym. Compos. 35 (2014) 1636-1643.

[27] S. Saravanan, Kishore, P.C. Ramamurthy, G. Madras, Polym. - Plast. Technol. Eng. 53 (2014) 684-692.

[28] P.J. Bora, K.J. Vinoy, P.C. Ramamurthy, Kishore, G. Madras, Electron. Mater. Lett. 12 (2016) 603-609.

[29] P.J. Bora, N. Mallik, P.C. Ramamurthy, Kishore, G. Madras, Compos. Part B Eng. 106 (2016) 224-233.

[30] P.J. Bora, K.J. Vinoy, P.C. Ramamurthy, Kishore, G. Madras, Mater. Res. Express 2 (2015) 036403.

[31] J. Sudagar, J. Lian, W. Sha, J. Alloy. Compd. 571 (2013) 183-204.

[32] Z.W. Liu, _ L.X. Phua, Y. Liu, C.K. Ong, J. Appl. Phys. 100 (2006) 093902.

[33] S.-.T. Kim, S.-.S. Ki, J. Appl. Phys. 115 (2014) 17A528.

[34] L.F. Chen, C.K. Ong, C.P. Neo, V.V. Varadan, V.K. Varadan, Microwave Electronics: Measurement and Materials Characterization, John Wiley \& Sons, 2004.

[35] B. Zhao, X. Guo, W. Zhao, J. Deng, G. Shao, B. Fan, Z. Bai, R. Zhang, ACS Appl. Mater. Interfaces 8 (2016) 28917-28925.

[36] P.J. Bora, M. Porwal, K.J. Vinoy, P.C Kishore, Ramamurthy, G. Madras, Compos. Part B Eng. 134 (2018) 151-163.

[37] B. Zhao, X. Guo, Y. Zhou, T. Su, C. Ma, R. Zhang, J. Mater, Chemistry A 3 (2015) 10345-10352.

[38] S. Liu, M. Zhang, X. Lv, Y. Wei, Y. Shi, J. Zhang, Appl. Phys. Lett. 113 (2018) 083905.

[39] Y. Wei, Y. Shi, Z. Jiang, X. Zhang, H. Chen, J. Alloys Compd. 810 (2019) 151950.

[40] G. Mu, H. Shen, J. Qiuc, M. Gu, A. Surf. Sci. 253 (2006) 2278-2281.

[41] Y. Wei, L. Zhang, C. Gong, S. Liu, M. Zhang, Y. Shi, J. Alloy. Compd. 735 (2018) 1488-1493.

[42] X. Zhang, J. Guo, P. Guan, G. Qin, S.J. Pennycook, Phys. Rev. Lett. 115 (2015) 147601.

[43] Y. Shi, M. Zhang, X. Zhang, L. Zhang, J. Appl. Phys. 126 (2019) 105109.

[44] X.G. Liu, B. Li, D.Y. Geng, W.B. Cui, F. Yang, Z.G. Xie, D.J. Kang, Z.D. Zhang, Carbon N. Y. 47 (2009) 470-474.

[45] Z. Liu, R. Che, Y. Wei, Y. Liu, A.A. Elzatahry, D. Zhao, APL Mater. 5 (2017) 046104.

[46] M. Ignatenko, M. Tanaka, Physica B 405 (2010) 352-358.

\section{Further reading}

[47] B. Zhao, X. Guo, Y. Zhou, T. Su, C. Ma, R. Zhang, CrystEngComm 19 (2017) 2178-2186. 